\title{
El Panorama: una manifestación artística marginal del siglo XIX
}

\author{
Mª Dolores Bastida de La CALLE*
}

RESUMEN: ABSTRACT:

El Panorama, una forma de arte de la revolución industrial, consistía

en gigantescas pinturas circulares con una visión central de $360^{\circ}$, en las que se mezclaba arte y técnica.

Estas pinturas circularon por las principales ciudades de Europa y

América, París, Londres, Nueva

York y atrajeron a un gran número de espectadores, lo que hizo posible el desarrollo del Panorama como una actividad empresarial. Al igual

que otro fenómeno artístico marginal del siglo XIX, la revista ilustrada de actualidad, el Panorama debió su gran popularidad a una cultura visual de medio de masas, basada en un afán de saber y conocer, fruto de la filosofía positivista de la época.
Panoramas were huge circular paintings with a $360^{\circ}$ central view that mixed art and technique into an artistic form characteristic of the industrial revolution. These paintings traveled to the great european and American cities, Paris, London, New York, and attracted large crowds of spectactors, that allowed the Panorama to develop as a commercial activity. In a way similar to another marginal artistic manifestation of the $19^{\text {th }}$ century, the illustrated magazine, the Panorama owed its popularity to a massmedium visual culture, that was based on a desire for knowledge, result of the positivist philosophy prevalent at the time.

"La arquitectura comienza a emanciparse del arte en las construcciones de hierro; la pintura lo hace a su vez en los panoramas". Con estas palabras anunciaba Walter Benjamin que los panoramas suponían una revolución en la relación del arte con la técnica, así como la expresión de un nuevo sentimiento vital en el siglo XIX1. La historia del Panorama como una particular combinación de arte y técnica comienza a incubarse en los primeros años del XIX, y obedece a un ansia de descubrir, de saber y de conocer, resultado de una cultura visual imbuida por la filosofía positivista de la época.

\footnotetext{
* Departamento de Historia del Arte. UNED.
}

1 BEJAMIN, Walter : Poesia y Capitalismo. lluminaciones II. Madrid, Taurus, 1991, pág. 176. 


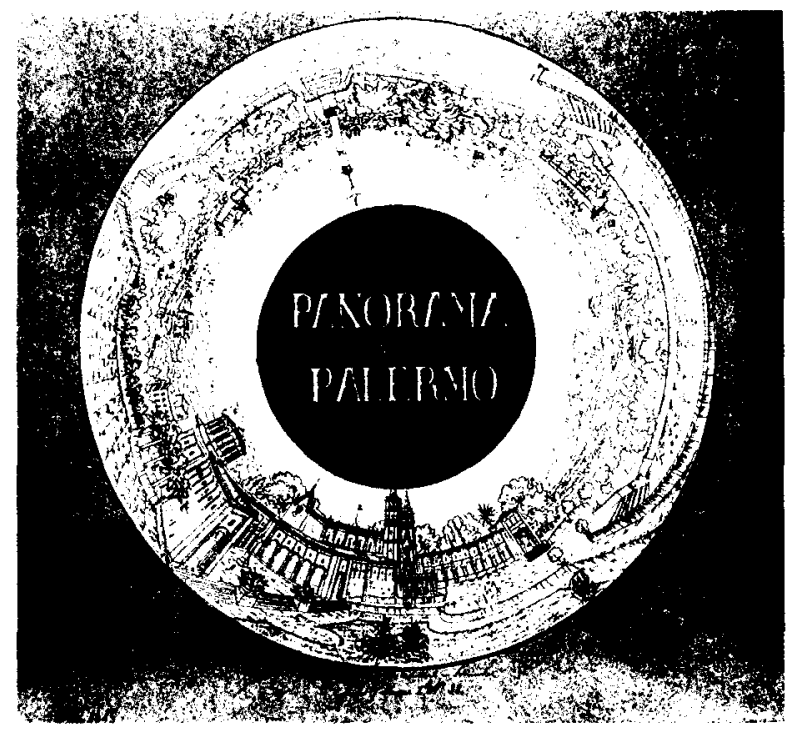

Fig. 1

Prospecto del

Panorama de

Palermo, 1808.

El término Panorama se utilizó en el siglo XIX para designar gigantescas pinturas circulares, que eran la generalización lógica de la perspectiva renacentista, un tipo de pintura que permitía una visión de $360^{\circ}$ al espectador, a quien siempre se le entregaba un prospecto que enfatizaba esa visión circular (Fig.1). La idea, sin embargo, había sido concebida en 1788 por Robert Barker, un irlandés residente en Edimburgo, quien exhibió una vista de la ciudad pintada en papel sobre un círculo de lienzo de ocho metros de diámetro. Muy poco después, ya en 1800, se creaban en París simultáneamente dos panoramas: "Una vista de París desde el tejado de las Tullerias» y "La evacuación de Toulon por los ingleses en 1793». Por otra parte, es interesante señalar, aunque quizás sea difícil de valorar, la importancia que tuvo la tradición topográfica del siglo XVII en Inglaterra en el origen y desarrollo del Panorama. La llegada de Canaletto a Londres en 1746 potenció notablemente la escuela topográfica de pintores ingleses, que popularizaron las vistas de Londres con detallados edificios delineados por el pincel, lo que sugiere una demanda por este tema2.

La compleja técnica pictórica necesaria para la realización de un Panorama evolucionó con el tiempo y terminó estandarizándose. Una gran superficie de lienzo, con típicas medidas de 15 metros de alto por 120

2 HAYES, John: "A Panorama of the City and South London", en Burlington Magazine, vol. 107, (1965), págs. 458.462. 


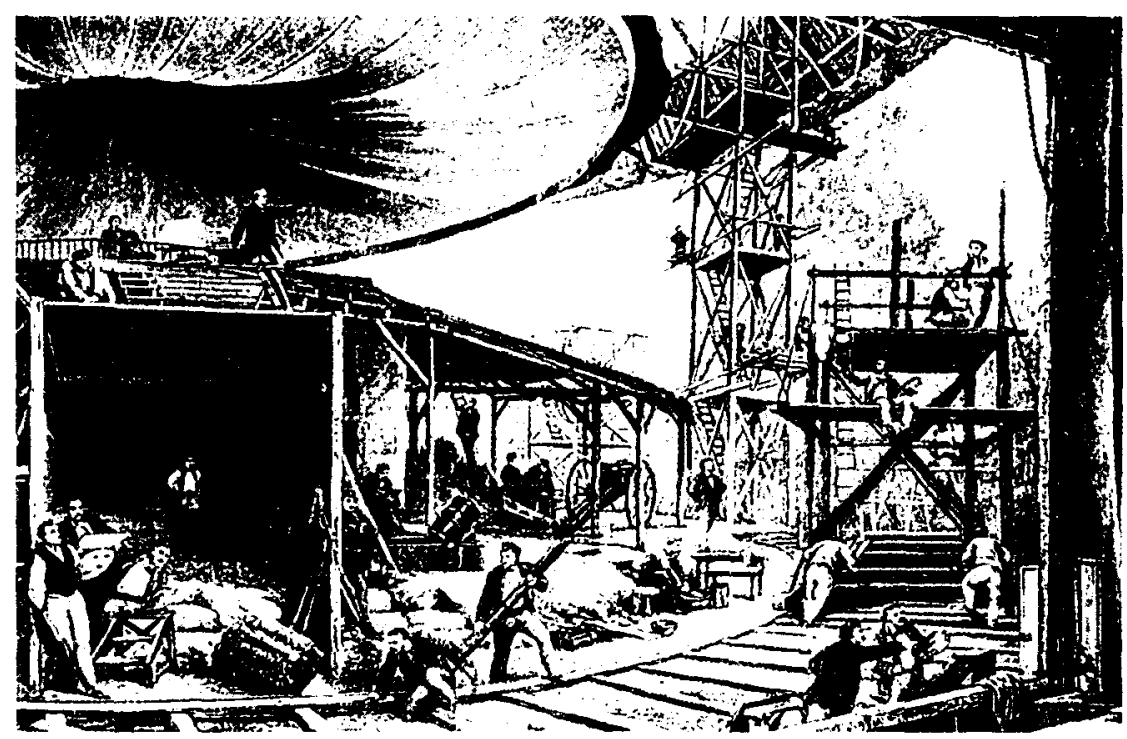

Fig. 2 Felix Philippoteaux coordinando la producción del Panorama "El asedio de Paris", en los Campos Elíseos, en 1873

metros de largo se exhibia en un edificio circular, una rotonda, especialmente diseñada al efecto. La rotonda permitía a un artista coordinador ver el progresivo desarrollo de la pintura desde el punto en que lo vería mas tarde el espectador: una plataforma central (Fig.2). El lienzo se colgaba de un aro de hierro, fijándose otro aro en la parte inferior a medio metro del suelo. De este aro se sujetaban pesos o grandes piedras para obtener una superficie perfectamente lisa. Para facilitar el trabajo a los artistas circulaba en torno a la rotonda un andamio movible sobre railes ${ }^{3}$. Hacia los años treinta del XIX apareció el panorama narrativo, que mostraba la pintura a medida que la enorme banda de lienzo se desenrollaba de un carrete gigante e iba enrollándose en torno a un segundo carrete. Se podría decir que ésta técnica anticipaba, de alguna manera, el moderno film del cine, y era también recuerdo de la antigua pintura china en seda, o papel, guardada en rollos.

Resulta obvio que la escala y complejidad de esta tarea pictórica excedia la capacidad de un solo artista, to que hizo necesaria una labor de equipo. Artistas encargados de recoger sketches preliminares desde un punto de vista alto, los trasladaban a grandes pliegos de papel -en cier-

3 TELBIN, William: “The Painting of Panoramas", en Magazine of Art, vol. 24, (1900), págs. 555-558. 


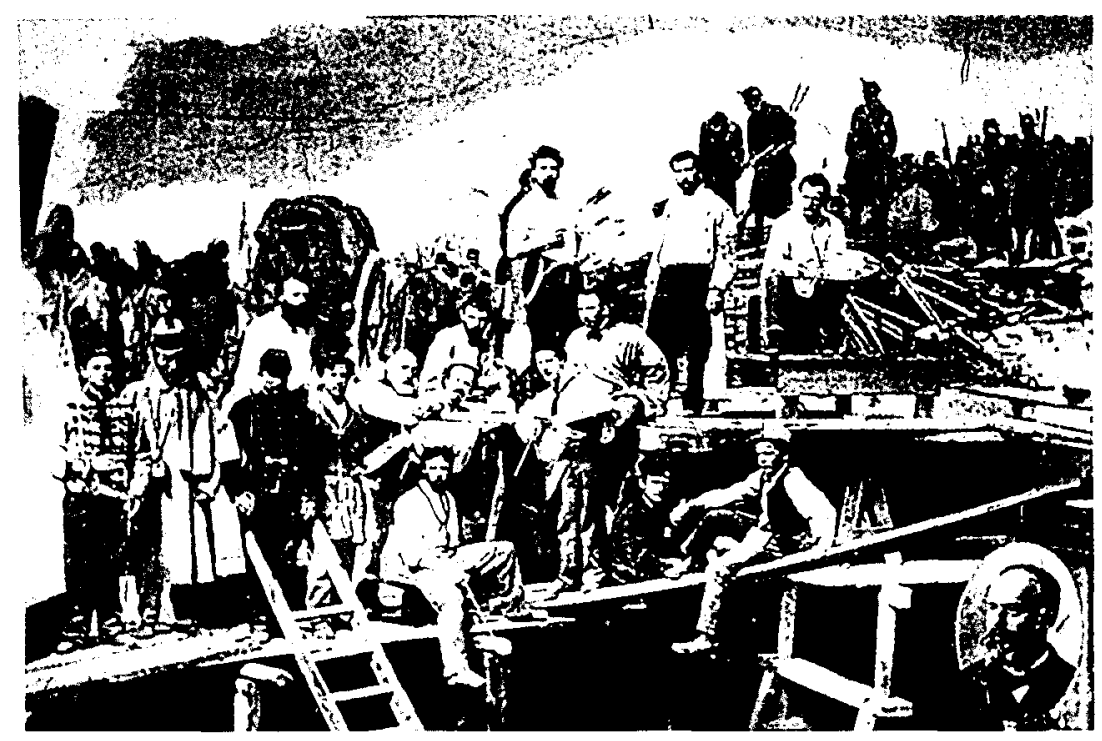

Fig. 3.- Equipo de pintores en la producción de un Panorama.

tos casos al lienzo- que posteriormente cosian en tiras de unos 3 metros de ancho, cuidando que las costuras quedasen totalmente planas. El boceto resultante se estiraba en torno a la rotonda justo debajo del techo y se procedía a la pintura. Usualmente se empezaba a pintar por el cielo. Como se ha dicho anteriormente, un artista coordinaba el trabajo desde una plataforma central, para indicar correcciones a los artistas, cuya posición no permitía percibir lo pintado en una perspectiva apropiada; esa supervisión estuvo, a veces, en manos de nombres famosos como Daguerre o Prevost. En el equipo artístico había especialistas en paisaje, arquitectura, figura humana y animales. Usualmente esos pintores tenían a su vez un pequeño número de ayudantes, que eran en su mayoria estudiantes de arte (Fig.3).

Es curioso que toda esta complejidad técnica del panorama guarda cierta similitud con otro fenómeno artístico marginal: la revista ilustrada de actualidad, que al igual que el panorama, adquirió en el siglo XIX una relevancia especial como fenómeno de masas. El éxito de esas revistas descansaba, también, en una detallada división del trabajo, con artistas corresponsales que recogían el boceto in situ, dibujantes de estudio, y un equipo de xilógrafos grabadores, con especialistas en diferentes temas, que cuidaban que la unión de los tacos de madera que formaban la matriz fuese perfecta para que no se notara en la página impresa. 

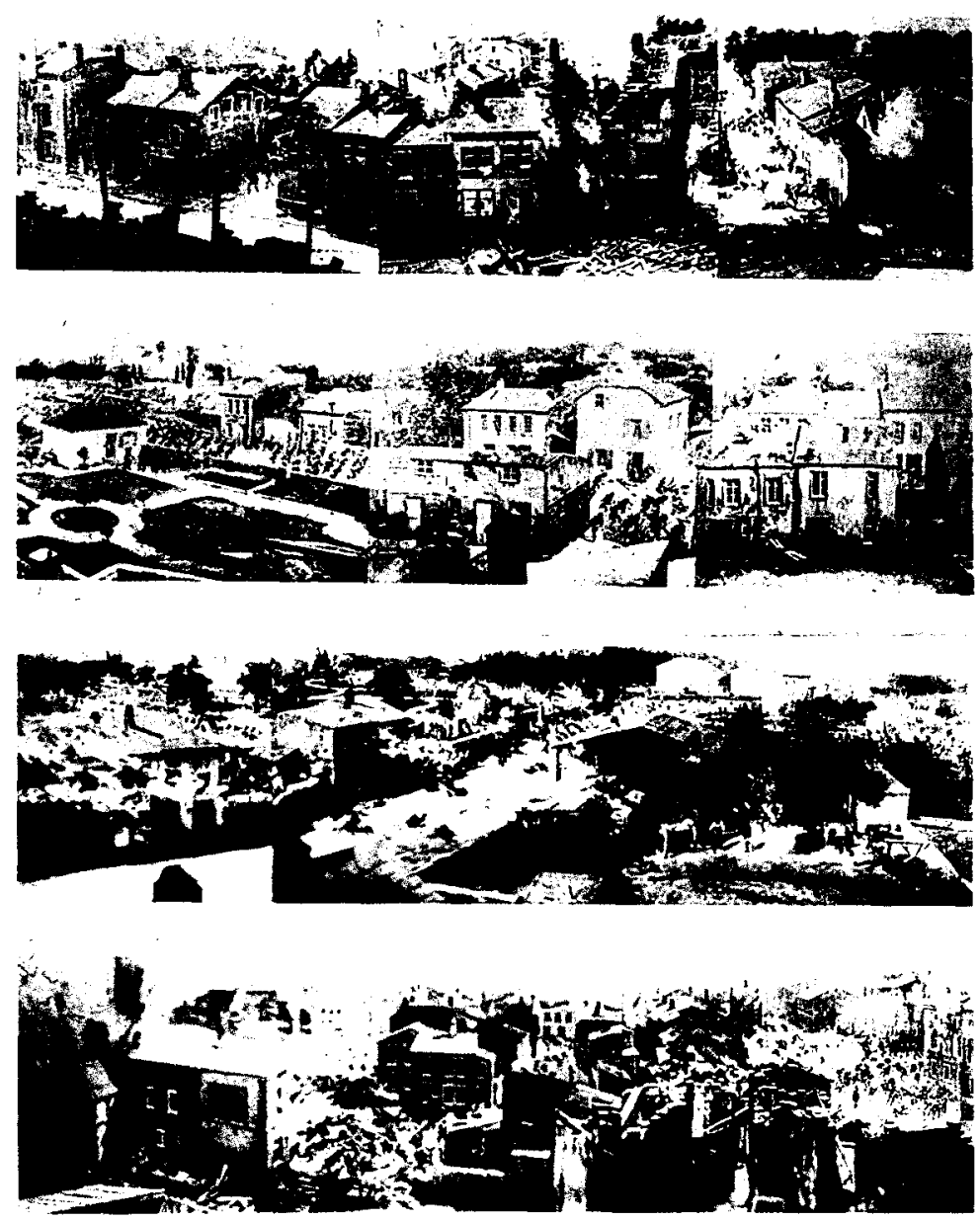

Figs. 4 y 5.- Panorama del combate en las calles de Bazeilles, en la Guerra Franco-Prusiana, 1870-71.

Tanto la revista ilustrada como el panorama compartían un medio social receptivo a la información y al entretenimiento, y coincidían en el deseo de poner al alcance de un público masivo, entre otros temas, acontecimientos de la vida de una nación. En ambas técnicas se descubrió pronto que la guerra era uno de los temas de mayor éxito (Figs. 4 y 5). Al igual que en la guerra civil americana los lectores buscaban reconocer a sus familiares en las estampas de las revistas, era usual la visita de un antiguo soldado a un panorama de tema bélico, acompañado de familiares y amigos, para mostrarles «in situ» su participación en la batalla. 

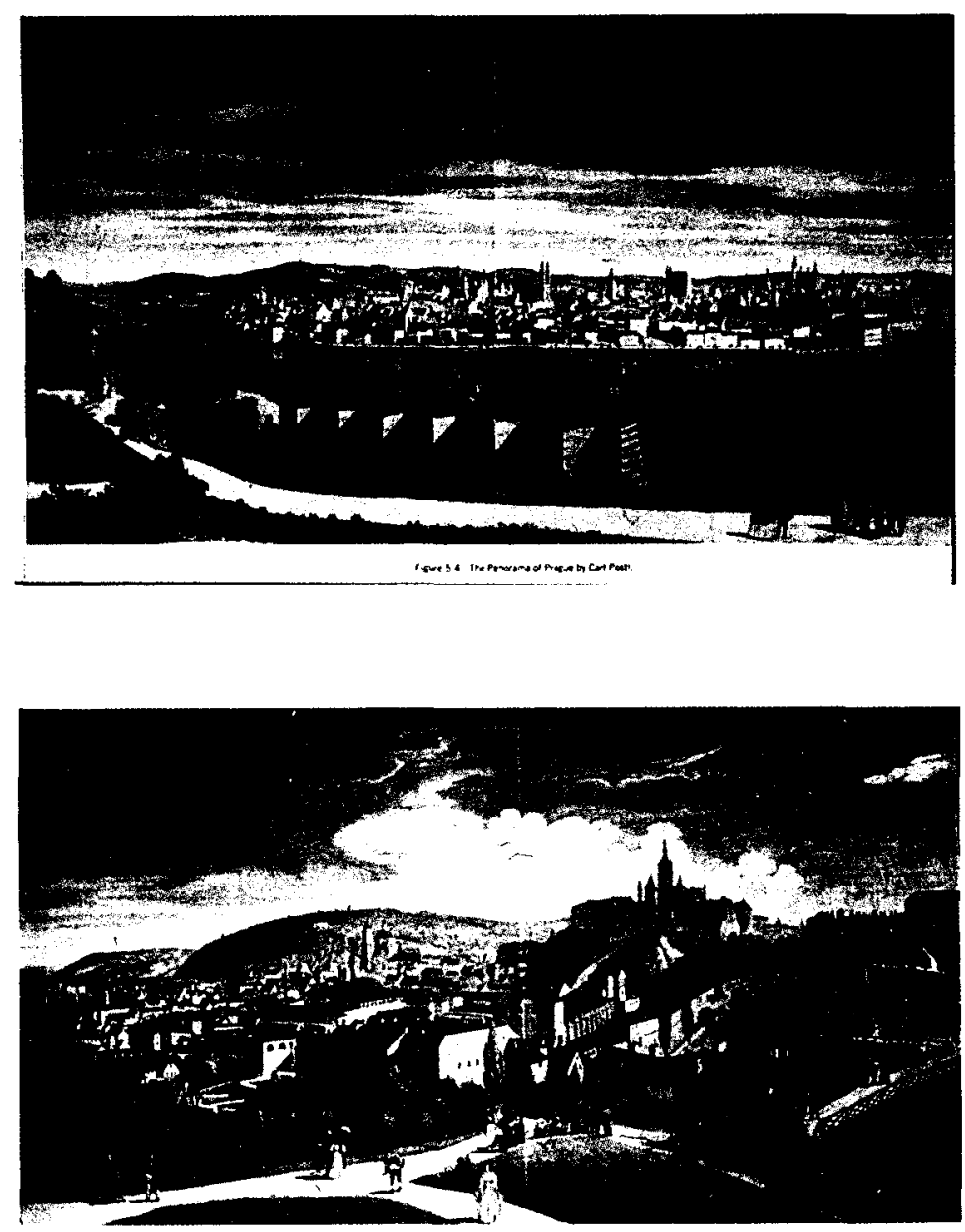

Figs. 6 y 7.- Panorama de Praga.

Detaille y de Neuville, que introdujeron el detallismo positivista en la pintura de escena bélica de la segunda mitad del XIX, fueron ellos mismos pintores de panoramas.

Aunque el panorama realizó una descripción general de una sociedad de la cual, de algún modo, fue portavoz de deseos y frustraciones, es en las reproducciones de imágenes y vistas de ciudades donde alcanzó máximo esplendor (Figs. 6 y 7). Este sentimiento coincidía de modo natural con la invitación de Baudelaire a los artistas a pintar la ciudad, porque «la 
vida de nuestra ciudad es rica en temas poéticos y maravillosos"4. Imágenes de ciudades especialmente valoradas por su realismo documental y sus convincentes perspectivas, a modo de vista de pájaro, se exhibian en las rotondas de las principales metrópolis de la época : Londres, París, Nueva York. Chateaubriand, en el prefacio a sus obras completas, comentó su visita a los panoramas de Prevost sobre Jerusalén y Atenas: "yo reconocí al primer vistazo todos los monumentos, todos los lugares y hasta la habitación que ocupé en el Monasterio de San Salvador. Nunca el relato de un viajero fue sometido a prueba tan difícil. Yo no podía haberme imaginado que transportasen Jerusalén y Atenas a París»5.

El ansia por descubrir nuevos países, nuevos escenarios, adquirió un considerable desarrollo durante el siglo XIX; era el momento de la expansión hacia el oeste americano, $y$, sin duda, en todo ello tuvo gran influencia el movimiento romántico. El espectáculo ilusionista que ofrecía el panorama satisfacía esa necesidad de viajar. El espectador perdía el sentido del espacio y la distancia al verse inmerso en una pintura extremadamente realista, con una escala y perspectiva tan perfectas, que en ausencia de cualquier medio de comparación con lo real, permitía a la gente realizar un sueño de la época: viajar sin tener que desplazarse; participar en el presente de algo que estaba lejos en el espacio o en el tiempo. El público que frecuentaba los panoramas, un grupo social desigual, de la clase media al proletariado urbano semiletrado, al que resultaba difícil viajar, pretendia conquistar el espacio a través de la pintura. El panorama ofrecía al espectador un modelo que le llevaba a dirigir su mirada de un extremo a otro, sin ceñirse a un punto concreto, al modo de ver el paisaje de los viajeros. Aún con la mejora de los medios de transporte, como el ferrocarril en particular, su utilización para largos viajes fue exclusiva de escritores, artistas y militares.

Por otra parte, el Panorama, junto a estos objetivos de espectáculo y entretenimiento, compartía otras consideraciones de carácter educativo y comercial. Su potencial formativo, cuyo valor fue reconocido por Dickens y Ruskin, consistía en informar y educar al público, tal como ocurrió en la Gran Exposición de 1889, con el Panorama de Poilpot sobre el Petróleo, que mostró una excelente lección de ciencia incluyendo folletos explicativos para los visitantes 6 . Por otra parte, el Panorama fue una forma de

4 COVEN, Jeffrey: Baudelaire's Voyages. The Poet and his Painters. Boston, Bulfinch Press, 1993, pág. 89.

5 BAPTS, Germain: “Essai sur L Histoire des Panoramas et des Dioramas" en The Prehistory of Photography. Editado por Robert Sobieszek. Nueva York, Arno Press, 1979, pág. 18.

6 COMMENT, Bernard: The Painted Panorama. Nueva York, Harry N. Abrams, 1999, pág. 117. 


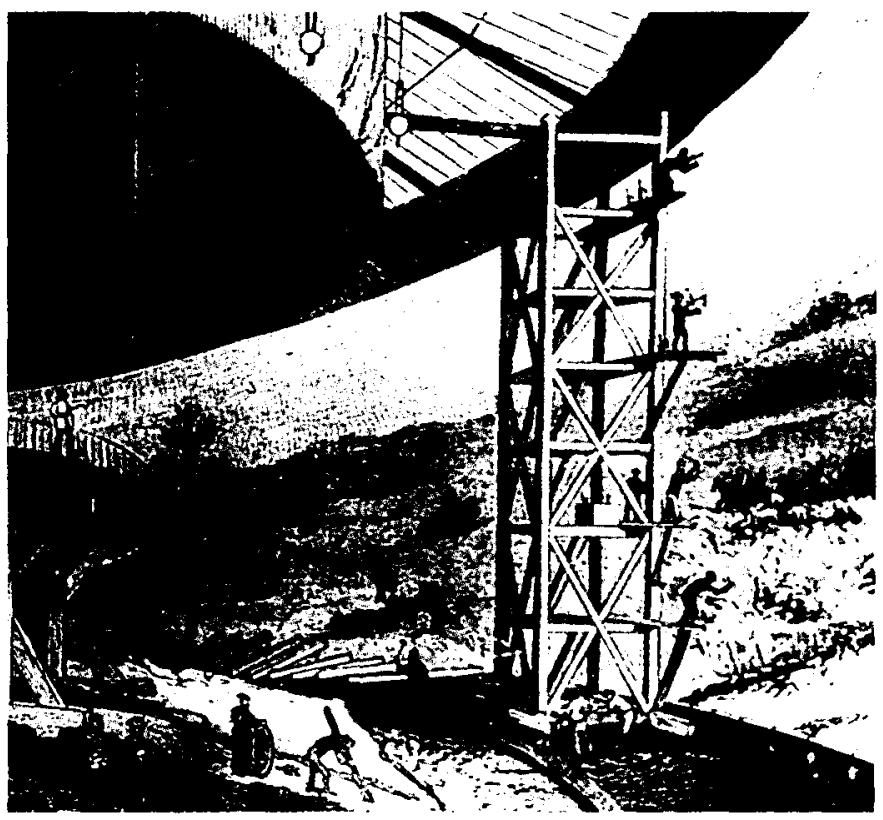

Fig. 8.

Interior de la rotonda de un panorama poco antes de completarse la pintura.

arte de la revolución industrial, que se financiaba con la asistencia de anónimos ciudadanos que acudian a presenciarlo, y era, por tanto, una actividad comercial.

La experiencia óptica cuya manifestación extrema permitía una visión sin límites en un circulo de $360^{\circ}$ no se redujo a la controvertida forma de arte del panorama (Fig.8). Ciertos elementos concomitantes permiten hablar de un fenómeno que abarcó todo el siglo XIX, el panoramismo7, un término que se ha utilizado en sentido metafórico para denominar un campo de visión amplio en algún área de conocimiento, como, por ejemplo, en literatura misma, al hablar de la percepción global de Balzac en su Comedia Humana, o en arte al referirse a ciertas pinturas de formato horizontal que por sus dimensiones nos recuerdan a los panoramas, como el cuadro de James Abbott McNeill Whistler "Harmony in Blue and Silver: Trouville", con dimensionesde de $6 \times 9$ metros. Otro caso es el de los pin-

7 Ibidem, pág. 139. 
tores de la escuela americana del río Hudson que comunicaron el sentimiento romántico del paisaje al modo del panorama: una respuesta al deseo interior de expresar visualmente la experiencia del espacio, como en el cuadro anónimo «Artist Painting A Panoramic view of Harrisburg, Pensylvania»8.

Enfoques estéticos análogos al panorama se encuentran, también, en pinturas de Caspar David Friedrich. Un ejemplo es «El caminante sobre la niebla", que data de 1818. Al igual que el espectador en la plataforma central de una rotonda panorámica, el viajero de Friedrich se alza sobre un saliente de roca, en medio de un extenso paisaje que le circunda. Por otra parte, la niebla que envuelve a las montañas y emerge ante él produce la impresión de que la iluminación viene del fondo; esta disposición luminíca recuerda al Panorama, donde la luz cenital de las rotondas se refleja en las paredes.

Stephan Oettermann ha sugerido que hay un cierto contenido social en los cuadros de Friedrich. «Lo que Friedrich ofrecería en sus pinturas no sería tanto un panorama como una pintura del mundo visto como un panorama.» En sus cuadros con figuras vistas de espaldas, Friedrich describe paisajes no transformados por el hombre. "Son paisajes deshabitados e impenetrables que parecen desafiar cualquier sentido de propiedad de la tierra. No hay rastro de vallas o muros - y esto en una época en que ei cercado del campo en algunos países señalaba cambios profundos en la relación entre la naturaleza y su uso." Esa apropriación de la naturaleza que ofrecería Friedrich aparece como un principio básico del panorama: las gentes que no eran propietarios de tierras podían disfrutar de una peculiar apropriación visual del campo a cambio de un ticket que les permitia la entrada al Panorama. En la inclusión de una figura humana que refleja la relación entre Panorama y espectador se querría adivinar los conflictos de la emergente era capitalista9.

Por otra parte, se podría argüir que el Panorama no fue una curiosa aberración en el mundo del arte, sino la respuesta a un problema que interesaba a algunos artistas. La moderna emoción de la gente del XIX por la experiencia del horizonte, esa línea que separa la realidad de la posibilidad, potenció la idea de crear ese elemento espacial. Gentes como el fotógrafo Nadar subieron a la góndola de un globo para tomar fotografías

8 BORN, Wolfgang: "The Panoramic Landscape as an American Art Forum", en Art in America, vol. 36, (1948), págs. 3-10.

9 OETTERMANN, Stephan: The Panorama. History of a Mass Medium. Nueva York, Zone Books, 1997, pág. 47. 


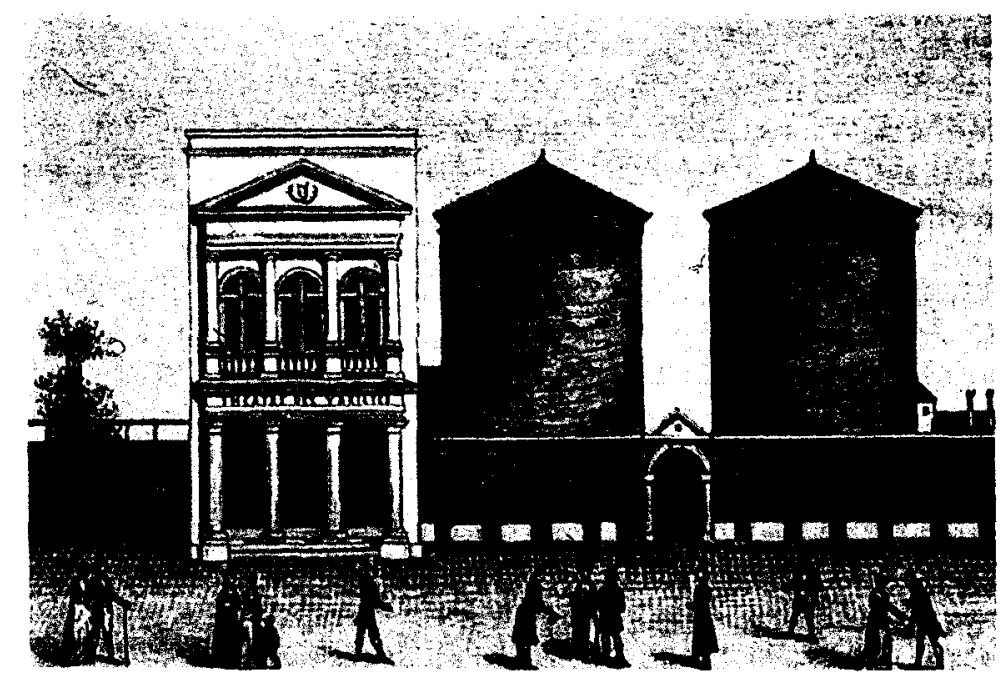

Fig.9.- Rotondas de Panorama en el Boulevard de Montmartre, Paris, 1802.

de un París ilimitado hasta el horizonte, ejemplo que recogen los grabados de la época. También en multitud de libros de viajes, obras literarias, memorias y cartas del XIX, se encuentran bocetos tomados desde un punto de vista alto; y a finales del siglo se habían levantado cientos de plataformas y torres como puntos de observación: la torre Eiffel y la estatua de La Libertad serían las más conocidas ${ }^{10}$.

En esta forma panorámica de registrar la experiencia visual, los edificios o rotondas, nombre con el que se denominaba esta forma especial de arquitectura, jugaron un rol importante (Fig.9). Se trataba de construcciones, usualmente de madera, que al iluminarse con velas o gas, acabaron, la mayoría, siendo destruidas por el fuego. El nombre más famoso conectado con las rotondas corresponde a un inmenso edificio, el Colosseum, llamado así a pesar de su parecido al Panteón de Roma. El Colosseum se construyó en el Regent Park de Londres en 1829, para exhibir un enorme panorama de la ciudad. Su autor, el artista Thomas Horn, levantó un andamio sobre la linterna de la catedral de San Paul para trabajar durante todo el verano en la recogida de bocetos, unos trescientos, comenzando a las tres de la madrugada día tras día. El año que el Colosseum se abrió al público atrajo a un millón de visitantes ${ }^{11}$. Esta enorme

11 NEEDHAM, Gerald: $19^{\text {th }}$ Century Realist Art. Nueva York, Harper and Row, 1988, pág. 15. 
Fig. 10.-

Vista interior del Colosseum, con su plataforma elevada, en Regent's Park, 1829.

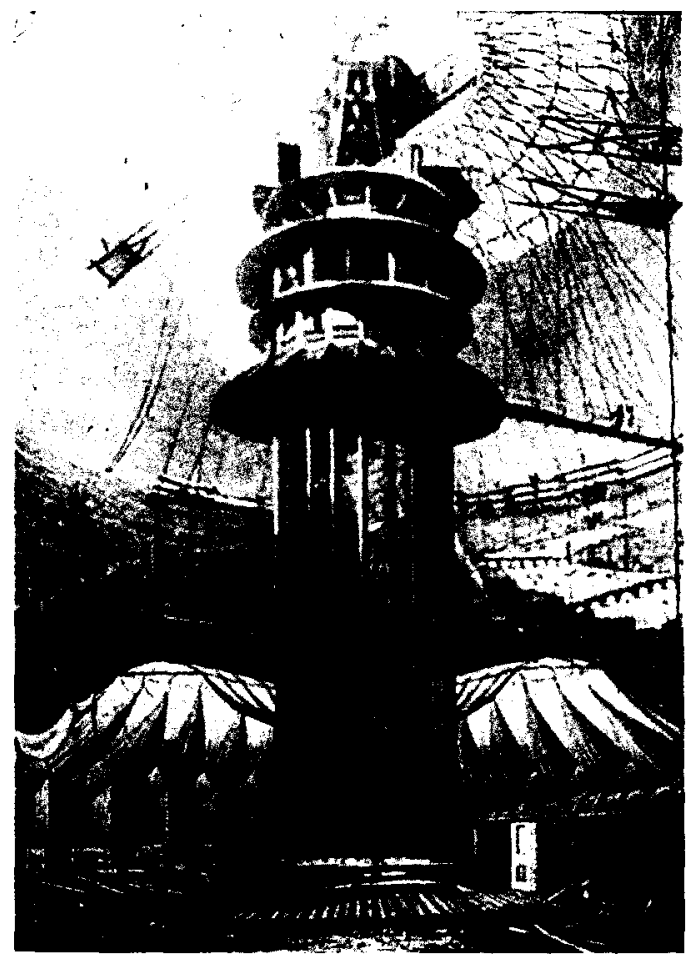

popularidad evidencia el ansia del público por la verosimilitud con respecto a esta controvertida forma de arte, en la que los efectos de luz y el detallismo minucioso de la representación, producian, a veces, una situación idealizada y engañosa a la cual, naturalmente, el cine puso fin con el cambio de siglo (Fig. 10).

El estilo esencialmente panorámico de rotonda se extendió a la exposición de ciertas pinturas, como en el caso de Monet y las dos composiciones sobre las Nympheas (1916-1925) en el Museo de l'Orangerie, en una ampliación dispuesta por el primer ministro francés Clemenceau con motivo de la donación, patriótica, que Monet habia hecho de las citadas pinturas. Sobre las curvadas paredes de dos galerías de forma oval se alineaban cuatro secciones de pinturas en forma de friso, compuesto de paneles que medían cada uno de ellos $2 \times 12.7$ metros y $2 \times 16.9$ metros respectivamente. Las grandes secciones panorámicas se componian de imágenes continuas, libremente estructuradas por los cambios en la armonia de color y tono en la Galeria I, y por el enmarcado de las siluetas de los árboles en la Galería II12. Una mirada análoga y cercana al panorama llegó, asimismo, al medio fotográfico. Un ejemplo sería el caso de 


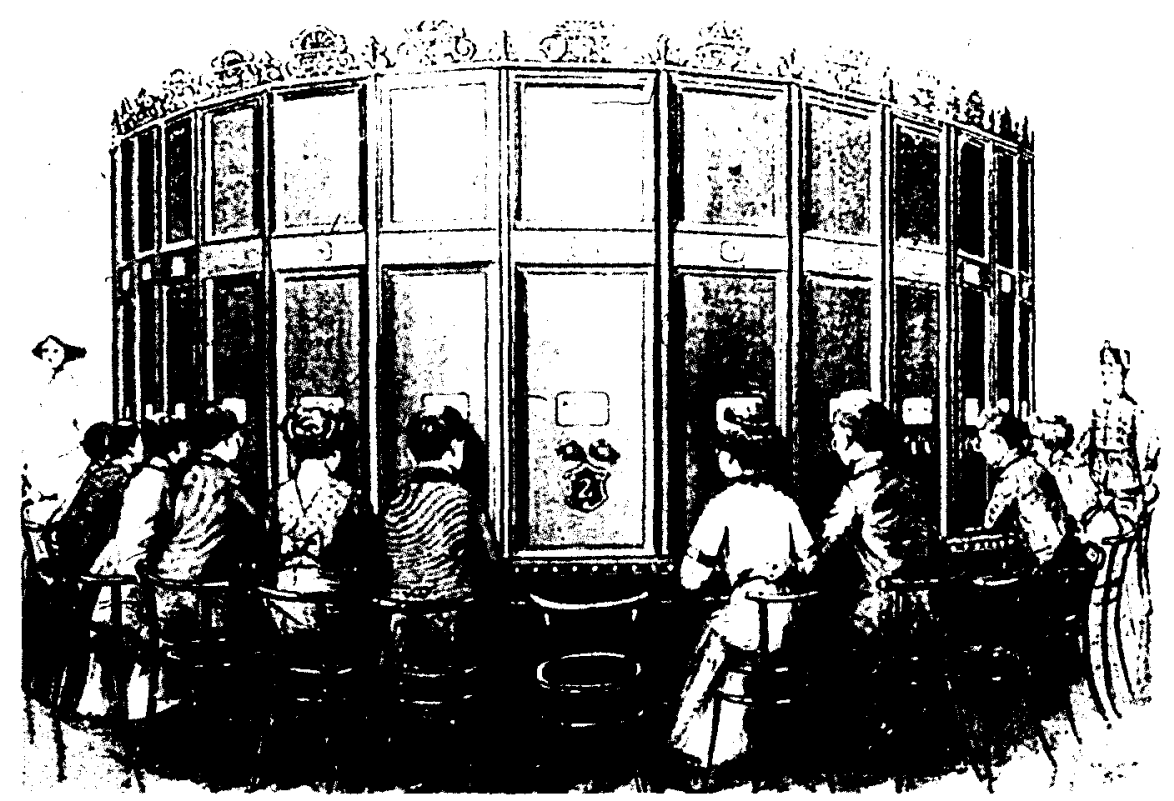

Fig. 11. - Panorama Kaiser, Berlín, 1883.

Muybridge con fotografía panorámica de una vista de $360^{\circ}$ de San Francisco, o incluso sus estudios del movimiento, otra forma de panorama fotográfico obtenida mediante la manipulación del espacio y el tiempo. Aunque esos estudios podrían considerarse más instrumento de ciencia que de arte, el propósito final sería el mismo13.

Por otra parte, el uso mismo de la fotografía influyó en la elaboración de una variante del panorama: el Panorama Kaiser (Fig.11), que el físico August Fuhrmann instaló en Berlín en 1883, y que pervivió 56 años, hasta 1939. Aunque no se puede hablar de un Panorama propiamente dicho, sino de un carrusel cilíndrico de madera con lunetos en su parte externa a través de los cuales los espectadores podian ver dos colecciones de 50 vistas que cambiaban dos veces por semana, el Panorama Kaiser se valoró, sobre todo, como instrumento educativo. Fuhrmann envió a fotógrafos por todo el mundo, a recoger información de lugares exóticos y de acontecimientos relevantes. De este Panorama, Franz Kafka llegó a decir

12 EITNER, Lorenz: An Outline of $19^{\text {th }}$ Century European Painting. From David through Cézanne. Nueva York, HarperCollins, 1992, pág. 365.

13 WESTERBECK, Colin L.: «Taking the Long View», en Art Forum, vol. 16, (1978), págs. 56-59. 
que «las imágenes son más naturales que en el cine porque, igual que en la realidad, permiten que la mirada se detenga. Los objetos que muestra el cine se mueven torpemente; me parece que el detener la mirada es más importante» 14 .

Para concluir, es interesante señalar que, no sólo el cine sino también el otro fenómeno de masas coetáneo en el XIX con el panorama, la revista ilustrada de actualidad, terminó poniendo fin a aquél cuando se hizo posible la impresión de fotografías. No obstante quedan según Bernard Comment unos 28 panoramas esparcidos por el mundo. De éstos, 23 están en rotondas especialmente construidas, otro está en el casino de Salzburgo, y 4 están en museos 15 . Por otra parte, existen panoramas de creación reciente como el "Panorama de la guerra árabe-israeli" encargado por el ejército egipcio y mostrado al público desde octubre de 1988 en una rotonda en Heliopolis; o el "Panorama de la ciudad de Bath» pintado por Roger Hallett, basado en fotografías tomadas desde un globo y exhibido en Bath desde 1988. Más recientemente, el pintor inglés David Hockney nos ha vuelto a recrear ese espectáculo provocador de emociones con las enormes vistas panorámicas del Gran Cañón de Colorado, exhibidas en la Royal Academy en junio de 1999. El artista ha declarado que desde el amanecer al atardecer recogía bocetos de lo que él llama "el gran agujero del mundo".

14 COMMENT, Bernard: Op. cit., pág. 257.

15 No se ha podido encontrar evidencia alguna de panoramas de vistas españolas ni de ningún panorama exhibido en Madrid o Barcelona. 
